\title{
Establishment of molecular genetic approaches to study gene expression and function in an invasive hemipteran, Halyomorpha halys
}

\author{
Yong $\mathrm{Lu}^{1,2+}$, Mengyao $\mathrm{Chen}^{1 \dagger}{ }^{1 \dagger}$ Katie Reding ${ }^{1}$ and Leslie Pick ${ }^{*}$
}

\begin{abstract}
Hemiptera is a large clade of insects understudied in terms of developmental biology. Halyomorpha halys, the Brown Marmorated Stink Bug (BMSB, referred to throughout as H. halys), is an invasive hemipteran pest of the mid-Atlantic region of the USA that has rapidly spread to other regions in recent years, devastating a wide range of crops using a piercing and sucking mechanism. Its phylogenetic position, polyphagous habits, and rapid spread in the USA suggested that $H$. halys would be an ideal system to broaden our knowledge of developmental mechanisms in insects. We and others previously generated transcriptome sequences from different life stages of this insect. Here, we describe tools to examine gene expression patterns in whole-mount $H$. halys embryos and to test the response of $H$. halys to RNA interference (RNAi). We show that spatial and temporal patterns of gene expression in $H$. halys can be effectively monitored by both immunostaining and in situ hybridization. We also show that delivery of dsRNA to adult females knocks down gene function in offspring, using the homeotic gene Sex combs reduced (Scr). Knockdown of HhScr resulted in dramatic malformations of the mouthparts, demonstrating for the first time that RNAi is effective in this species. Our results suggest that, despite difficulties with long-term laboratory culture of $H$. halys, this species shows promise as a developmental system.
\end{abstract}

Keywords: Brown Marmorated Stink Bug, H. halys, RNAi, Homeotic, Hemiptera, Engrailed, Scr, Even-skipped

\section{Background}

Most studies of arthropod evo-devo have utilized holometabolous insects, particularly Drosophila melanogaster, and, more recently, Tribolium castaneum ( $T$. castaneum) which are well-developed laboratory model systems with a wide array of resources available for communities of researchers [1-7]. The order Hemiptera, which includes at least 54 families of the true bugs (Heteroptera), is the largest non-holometabolous insect order with more than 80,000 described species $[8,9]$. Hemiptera are hemimetabolous insects, sharing piercing

\footnotetext{
*Correspondence: Ipick@umd.edu

${ }^{\dagger}$ Yong Lu and Mengyao Chen contributed equally to this work

1 Department of Entomology, University of Maryland, College Park, MD 20742, USA

Full list of author information is available at the end of the article
}

and sucking mouth parts that cause harm to both plants and animals, by virtue of direct physical damage, as well as by transmission of pathogens. The order includes major agricultural pests, such as aphids, stink bugs, and white flies, as well as pests of humans, such as kissing bugs, vectors of serious human disease (reviewed in [10, 11]). As is the case for hemimetabolous taxa in general, studies of hemipteran development have been underrepresented in the evo-devo field to date, limiting our ability to probe the origins of diversity within insects. Within the order Hemiptera, the milkweed bug Oncopeltus fasciatus (O. fasciatus, Hemiptera: Lygaeidae) is emerging as a model species (see, for examples, [12-18]). However, additional systems are required for comparative studies within the hemimetabolous insects, to understand both general rules controlling the development of insects that do not undergo metamorphosis, and to understand the 
developmental basis of novelties, including for example, the large differences in host preference (plant feeders vs. human hosts), color patterns, and habitat choice seen within this clade.

With an estimated divergence from $O$. fasciatus of 244 MYA [19], Halyomorpha halys, commonly known as the Brown Marmorated Stink Bug (H. halys, Hemiptera: Pentatomidae), represents a distant branch within Hemiptera, providing a useful phylogenetic point for comparative studies to O. fasciatus. H. halys is a polyphagous insect which feeds on tree fruits, vegetables, legumes, and ornamentals in the field and in nursery crops (reviewed in [20, 21]), as opposed to O. fasciatus, which is a highly specialized feeder. Another justification for studying $H$. halys is that it is a serious agricultural pest, which has caused significant damage in the Mid-Atlantic region of the USA in recent years [22, 23]. Studies of gene expression and gene function, as well as the ability to manipulate genes, will uncover information about the basic biology of $H$. halys, while providing novel means to make use of genetic approaches for pest control.

Here, we report the first molecular methods for $H$. halys. We have developed methods to examine spatiotemporal gene expression, using segmentation genes even-skipped (eve) and engrailed (en) for in situ hybridization. Using a cross-reactive antibody for En, we also provide methods for immunohistochemistry in $H$. halys embryos. Based upon the dramatic homeotic transformation of proboscis to leg seen after RNAi-mediated knockdown of the Sex combs reduced gene (Scr) in O. fasciatus, and in a cockroach $[15,24,25]$, we used this gene to test whether $H$. halys are capable of systemic responses to injected dsRNA. We found that injection of Scr dsRNA into adult $H$. halys females resulted in malformation of the mouthparts in their offspring, suggestive of homeotic transformation toward leg. These results provide a starting point for comparative evolutionary developmental studies in a thus far understudied hemipteran species, while also suggesting that RNAi can be an effective strategy to control $H$. halys pests.

\section{Methods}

\section{Insect husbandry and embryo collection}

Laboratory colonies of $H$. halys were initially reared as previously described [26]. Briefly, $H$. halys were collected in soybean fields at the University of Maryland Beltsville Research Farm. The collected $H$. halys were kept in mesh cages $(60 \times 30 \times 35 \mathrm{~cm})$. Potted green bean plants (Phaseolus vulgaris) were the major food source and hiding place for the bugs. Organic green bean pods and raw sunflower seeds were added to the cages to provide extra nourishment. These foods were replaced with fresh ones once or twice a week. All foods were certified organic and were washed extensively before placement in cages. Other diet supplements we tested included blueberries, apples, grapes, and carrots. We did not notice any difference in $H$. halys growth with these extra food sources. After several colony collapses using this approach, we switched to a rearing protocol kindly provided to us by Dr. Don Weber [27]. We grew a new colony from ten egg masses provided by Dr. Weber's laboratory. Different generations were kept separately, in order to track the health of our colony and keep the most reproductive individuals together. Briefly, eggs and first instar nymphs were kept in small petri dishes $(5.5 \mathrm{~cm}$ in diameter) with wet cotton and pieces of fresh organic green beans. When nymphs reached the second instar, generally after 5 days, they were moved to clean plastic cylindrical containers $(18.5 \mathrm{~cm}$ in diameter $\times 20.5 \mathrm{~cm}$ in height $)$ with fresh organic green bean pods, sunflower and buckwheat seeds, and wet cotton. A piece of fine plastic mesh screen $(32 \times 32$ mesh per inch) was also added to each adult cage as an egg-laying substrate. While $H$. halys egg masses stick to most surfaces fairly well, they can be easily peeled off of this plastic mesh. All $H$. halys cages were kept at $25{ }^{\circ} \mathrm{C}, \mathrm{RH}$ of $55 \pm 5 \%$, with a $16 \mathrm{~h}$ light:8 h dark photoperiod. Every other day, the green beans were replaced in all cages and petri dishes. At this time, egg masses and any dead adults were removed from adult cages; the numbers of clutches and dead males and females were recorded so that cage population and female fecundity could be tracked. For timed egg collections, cages were checked every $4 \mathrm{~h}$ for newly laid eggs. The eggs were removed from the cages and kept in petri dishes under the same environmental conditions described above until the desired time points were reached. Under these conditions, the overall life cycle (egg to fertile adult) was $\sim 1.5$ months, with eggs hatching to the first nymphal stage in 5 days and each subsequent instar lasting between 5 and 10 days.

\section{Identification of genes of interest}

Prior to availability of genome or transcriptome data, degenerate PCR was carried out to isolate regions of $H$. halys orthologs of engrailed (Hh-en) and Sex combs reduced (Hh-Scr). Primers were: Hh-en: DEGNenF 5'-GA RAAYMGNTAYYTNACNGA- ${ }^{\prime}$ and DEGenR $5^{\prime}$-RTGRT TRTANARNCCYTGNGC-3'; ScrdegF 5'-CCRCARATH TAYCCRTGGATG- $3^{\prime}$ and ScrdegR 1 5'-CATRTGGYA NGGNACRATRTTCAT- $3^{\prime}$. Sequences were verified by comparison with transcriptome data. Assembled $H$. halys RNA-seq data [28] in FASTA format were used to create a local $H$. halys BLAST database using the BLAST + package [29]. BLAST searches were carried out using the sequence of products generated by degenerate PCR, followed by TBLASTN using full-length $D$. melanogaster 
En or Scr protein sequences as the query sequences. To identify $H$. halys even-skipped (eve), full-length $D$. melanogaster Eve was used as query with the local $H$. halys BLAST database as the subject database. Reciprocal BLAST with the insect non-redundant protein sequence database was carried out to find orthologs. Predicted $H$. halys genes were experimentally verified by reverse transcription PCR (RT-PCR) followed by Sanger sequencing. Gene accessions: Hh-eve, GenBank: GBHT01012779.1; Hh-en, GenBank: GBHT01012041.1; Hh-Scr, GenBank: GBHT01003272.1 [28].

\section{Embryo fixation}

To collect embryos, the plastic mesh egg-laying substrate was removed from the cage and embryos were simply peeled off the mesh and dropped into 2-ml centrifuge tubes, with $\sim 20$ embryos per tube. Embryos for in situ hybridization and immunostaining were aged to $18-72 \mathrm{~h}$ after egg laying (AEL). The fixation protocol was modified from that developed for $O$. fasciatus, kindly shared by Dr. Ariel Chipman's laboratory [30]. In brief, $600 \mu \mathrm{l}$ of water was added to each tube of embryos which was placed in boiling water for $3 \mathrm{~min}$ and then placed on ice for $6 \mathrm{~min}$. After the water was removed, $600 \mu \mathrm{l}$ of heptane and $600 \mu \mathrm{l} 4 \%$ paraformaldehyde (PFA) in PBS (0.137 M NaCl, $0.0027 \mathrm{M} \mathrm{KCl}, 0.0015 \mathrm{M} \mathrm{KH}_{2} \mathrm{PO}_{4}$, $0.008 \mathrm{M} \mathrm{Na}_{2} \mathrm{HPO}_{4}$ ) were added. Gentle shaking brought the embryos to the interface. Tubes were shaken vigorously on a Vortex mixer for $20 \mathrm{~min}$. After shaking, the heptane and PFA were removed, and the embryos were rinsed once with heptane, then once with methanol. The embryos together with methanol were then put into wells on depression concave slides and the eggshells, which are rather thick in this species, were manually removed with forceps under a dissection microscope. The embryos were then passed through 75,50 , and $25 \%$ methanol/ PBST (phosphate-buffered saline, $0.05 \%$ Tween $^{\circledR} 20$ ) gradient rinses for rehydration. The rehydrated embryos were fixed with $4 \%$ PFA in PBST for $90 \mathrm{~min}$ on a nutator. The fixed embryos were then washed three times with methanol and stored in methanol at $-20{ }^{\circ} \mathrm{C}$ for future use.

\section{Immunohistochemistry}

Embryos were collected and fixed as described above, removed from $-20^{\circ} \mathrm{C}$, and passed through a 75,50 , and $25 \%$ methanol/PBST gradient for rehydration. Embryos were then rocked on a nutator in 5\% BSA in PBST for $2-3 \mathrm{~h}$ to block non-specific binding. After blocking, the embryos were incubated with a 1:10 dilution of monoclonal anti-Engrailed antibody 4D9 (Developmental Studies Hybridoma Bank) in $5 \% \mathrm{BSA}$ at $4{ }^{\circ} \mathrm{C}$ overnight. The $4 \mathrm{D} 9$ antibody was removed, and the embryos were washed three times for 20 min each with PBST. The embryos were then incubated with 1:300 biotinylated goat antimouse IgG antibody (Vector Labs) for $2 \mathrm{~h}$ at room temperature. The secondary antibody was then removed, and embryos were washed with PBST three times for $20 \mathrm{~min}$ each. After washing, the embryos were incubated $1 \mathrm{~h}$ with $A B C$ reagent (avidin-biotin complex, Vector Labs) followed by three 20-min washes with PBST. Detection by a color reaction was carried out using the SigmaFast DAB kit (Sigma-Aldrich). Expression was monitored under a dissection microscope and terminated when expression was evident, usually within $30 \mathrm{~min}$. The DAB solution was then removed, and embryos were rinsed three times with PBS. Embryos were post-fixed with 4\% PFA for 20 min rinsed with and transferred to PBST, and germband embryos were removed from the yolk using forceps. The post-fix was added because the yolk was very sticky, and the embryos were quite fragile and difficult to dissect. Adding methanol to PBST (1:1) was found to decrease the stickiness of the yolk and improve the dissections. Embryos were rehydrated in PBS and then transferred to $90 \%$ glycerol/PBS, where they were held overnight. Germ bands were mounted in $90 \%$ glycerol/ PBS. Photographs were taken under a dissection microscope (Leica M420, 16-20×).

\section{Whole-mount in situ hybridization}

Digoxygenin-labeled probes were made by in vitro transcription using PCR products as template, using the MEGAscript ${ }^{\circledR}$ T7 Transcription Kit (Life Technologies) following the manufacturer's recommendations. T7 promoter sequences were added to the reverse PCR primers for amplification of $H$. halys cDNA, generated from mixed-stage embryos. The primers used were: $H h-e n F$ 5'-TACCCTTCTCCGTCGACAAC-3' and Hh-enRT7 5'-TAATACGACTCACTATAGGGAGACGGCCTCTT GTCTTCTTTGT-3' generating a 252 bp fragment for Hh-en; Hh-eve $2 F$ 5'-AGGAGCATGTCATCGAG AAGG-3' and Hh-Eve2RT7 5'-TAATACGACTCACT ATAGGGAGAACTATCTTCCTGCTATCACTGGT- ${ }^{\prime}$ to amplify a 231-bp fragment including coding region and 3'UTR of Hh.eve. Embryos were fixed and rehydrated as described above. After rehydration, the embryos were pre-hybridized with hybridization buffer (50\% formamide, $5 \times$ SSC, $0.1 \%$ Tween $20,50 \mu \mathrm{g} / \mathrm{ml}$ yeast tRNA, $5 \%$ dextran, $50 \mu \mathrm{g} / \mathrm{ml}$ heparin) at $55{ }^{\circ} \mathrm{C}$ for $1-4 \mathrm{~h}$. After pre-hybridization, a 1:100 dilution of probe in hybridization buffer was added to the embryos and incubated at $55^{\circ} \mathrm{C}$ overnight $(16-18 \mathrm{~h})$. The probe was then removed, and the embryos were washed twice with hybridization buffer at $55{ }^{\circ} \mathrm{C}$ for $15 \mathrm{~min}$ each, followed by two washes in $2 \times \mathrm{SSC}$ at room temperature for $30 \mathrm{~min}$ and one wash in $0.2 \times \mathrm{SSC}$ at room temperature for $30 \mathrm{~min}$. The 
embryos were rinsed three times with PBST. After rinsing, the embryos were incubated with $10 \%$ sheep serum in PBST for 1-4 h at room temperature to block nonspecific binding. Embryos were then incubated with anti-digoxygenin-AP antibody (1:1500, Roche) at $4{ }^{\circ} \mathrm{C}$ overnight. After incubation, the antibody was removed, and the embryos were washed five times in PBST for $20 \mathrm{~min}$ each. For detection, the embryos were washed with staining buffer $\left(100 \mathrm{mM} \mathrm{NaCl}, 50 \mathrm{mM} \mathrm{MgCl}_{2}\right.$, $100 \mathrm{mM}$ Tris $\mathrm{pH}$ 9.5, 0.1\% Tween 20) three times for 5 min each. Staining was carried out using NBT/BCIP solution (Roche) diluted in staining buffer. The embryos were checked under a dissection microscope every 10 min until the desired color reaction had developed, generally within $1 \mathrm{~h}$. The color reaction was stopped by adding PBST to the staining solution. The embryos were then washed with PBST three times for 5 min each to remove the staining solution from the embryos. The embryos were washed with 50\% methanol in PBST for $5 \mathrm{~min}$ and $100 \%$ methanol for another $5 \mathrm{~min}$, and then placed in $100 \%$ ethanol for $30 \mathrm{~min}$ to $2 \mathrm{~h}$. The embryos were washed with 50\% methanol in PBST for $5 \mathrm{~min}$ and with PBST three times for 5 min each. Blastoderm stage embryos were transferred to depression slides to take pictures; germ band stage embryos were dissected out of yolk and mounted on slides with $90 \%$ glycerol. Photographs were taken under a dissection microscope (Leica M420, 16-20×).

\section{Double-strand RNA (dsRNA) synthesis}

Primers were designed to amplify a 327-bp region of $H$ h$S c r$, with T7 promoter sequences added to the $5^{\prime}$ end of both forward and reverse primers. Primer sequences: Hh-ScrFT7 5'-TAATACGACTCACTATAGGGAGAGCAGGACCTGACTACGTCCTC-3' and Hh-ScrRT7 5'-AATACGACTCACTATAGGGAGATCCAGCTCCAGCGTCTGGTA-3' (T7 promoter sequences underlined). PCR was carried out with cDNA that had been made from 0-to-6-day-old embryos using the manufacturer's recommended standard conditions (Reverse Transcription system, Promega). The PCR products were purified and sent out for sequencing (Genewiz) to confirm that the correct gene was amplified. The purified PCR product (Gel Extraction Kit, Qiagen) was used as the template for in vitro transcription using the MEGAscript ${ }^{\circledR}$ T7 Transcription Kit (Life Technologies) following the manufacturer's recommendations. The final product was treated with DNase from the transcription kit to degrade the DNA template. In order to anneal the in vitro transcription product single-stranded RNAs, transcription products were heated to $94{ }^{\circ} \mathrm{C}$ for $5 \mathrm{~min}$ and slowly cooled in a PCR machine by decreasing the temperature $0.8{ }^{\circ} \mathrm{C}$ every minute until $45^{\circ} \mathrm{C}$ was reached
(TPersonal, Biometra). The annealed double-strand RNA was precipitated with $1 / 10$ volume of $3 \mathrm{M}$ sodium acetate $(\mathrm{pH}, 5.2)$ and $2 \times$ volume of ethanol and was then dissolved in $20-40 \mu \mathrm{l}$ injection buffer $\left(0.1 \mathrm{mM} \mathrm{NaH} \mathrm{PO}_{4}\right.$, $5 \mathrm{mM} \mathrm{KCl}, \mathrm{pH} 6.8$ ), and stored at $-20^{\circ} \mathrm{C}$. The concentration of double-stranded RNA was measured with a NanoDrop spectrophotometer.

The dsRNA was injected into adult female $H$. halys using a Hamilton syringe and needle, as described previously for O. fasciatus [50]. H. halys females were anesthetized under $\mathrm{CO}_{2}$, and the Hamilton needle was inserted into the abdomen between the third and fourth abdominal sternites (Additional file 1: Figure 1). Each female $H$. halys was injected with 2-6 $\mu \mathrm{l}$ Scr dsRNA at a concentration of $3 \mu \mathrm{g} / \mathrm{ul}$. Four-to-ten individual females were injected in each experiment. After injection, the needle was held at the injection site for approximately $1 \mathrm{~min}$ to prevent leakage from the injection site. Injected females were kept separately for 1 day to allow for recovery before 2-3 males were added to each cage for mating. Eggs were collected and allowed to hatch, and defects were assessed in both hatched nymphs and unhatched embryos.

\section{Results}

Gene expression in whole-mount $\boldsymbol{H}$. halys embryos

Hh-engrailed (Hh-en) and Hh-even-skipped (Hh-eve) were isolated for this study because of their unique expression patterns and known functions in other insects, thereby serving as good candidate genes for the establishment of molecular staining techniques for $H$. halys. To isolate $H$ h-en, degenerate primers were used to amplify cDNA prepared from 1-to-5-day-old $H$. halys embryos. A sequence of $286 \mathrm{bp}$ was acquired and used as the query in a BLASTN search against the $H$. halys transcriptome database and compared with TBLASTN results. One 566-bp sequence was shared by both BLASTN and TBLASTN results and encodes a 188 amino acid region, which includes the 60 amino acid homeodomain. The $H h$-En homeodomain is $85 \%$ identical to $D$. melanogaster En, and $83 \%$ identical to $D$. melanogaster Inv. The Hh-En sequence does not have the RS-motif, which is found in Inv proteins [31,32], suggesting it is more closely related to En (Additional file 2: Figure 2a). Hh-eve sequence was identified through BLAST searches of the transcriptome data using the full-length $D$. melanogaster Eve protein sequence as query and orthology was confirmed by reciprocal BLAST. The Hh-eve sequence isolated encodes 221 amino acids. The homeodomain is $90 \%$ identical to that of D. melanogaster Eve (Additional file 3: Figure 2b).

In $D$. melanogaster, en is a segment polarity gene expressed in segmental stripes in the primordia of the posterior compartment of each segment [33, 34]. Similar segmental expression patterns for en were observed in a 
wide range of other species including all insects examined to date as well as more distant arthropods [35-38]. This high degree of conservation of expression makes en a useful marker for establishing techniques to monitor gene expression in embryos of diverse species, as it is expected to be expressed in clear, segmental stripes in early embryos of virtually any insect. This type of clear expression pattern allows one to distinguish false positive patterns from true patterns, as it is easy to tell which staining is background and which is a bona fide signal. Thus, we first characterized the expression of Hh-en in $H$. halys embryos using in situ hybridization protocols on early germ band stage $H$. halys embryos. As shown in Fig. 1a, Hh-en mRNA was detected by in situ hybridization in segmental stripes, as expected. To test whether in situ hybridization works for other genes expressed in early $H$. halys embryos, an ortholog of the D. melanogaster pair-rule gene (PRG) eve was isolated. In contrast to en, which is expressed segmentally throughout arthropods [36], orthologs of D. melanogaster PRGs vary in expression in different arthropod taxa (e.g., [39-43]). This in part reflects the fact that segments are specified more or less simultaneously at the blastoderm stage in D. melanogaster, reflecting its derived, long germ mode of development. In contrast, most other insects, including Hemiptera, specify only a small number of segments at blastoderm, with additional segments added sequentially from a growth or segment addition zone (short- or intermediate germ mode, reviewed in [44, 45]). Accordingly, Dm-eve is expressed in seven stripes in the $D$. melanogaster blastoderm in the primordia of segmental regions missing in eve mutants [46]. In contrast, in the hemipteran O. fasciatus, eve is expressed in the segment addition zone, with stripes emerging sequentially in elongating germ bands [47]. Hh-eve expression was detected in clear stripes in both blastoderm (Fig. 1c) and germ band stage (Fig. 1d) embryos. In blastoderm stage embryos, three Hh-eve stripes were detected in the central region of the embryo. This number of PRG stripes is suggestive of intermediate germ development, as only single eve stripes were observed at the blastoderm stage for short germ T. castaneum, while four eve stripes were observed for intermediate germ beetles [48, 49]. In elongating germband embryos, two Hh-eve stripes were detected at or just anterior to the segment addition zone (arrows), similar to what has been observed in other sequentially segmenting species. The position of these stripes suggests that Hh-eve is expressed segmentally in $H$. halys embryos, although further experiments, using double staining to definitively determine stripe register, are needed to confirm this.

To establish immunohistochemical techniques in whole-mount $H$. halys embryos, we used a monoclonal antibody raised against Dm-En (MAb 4D9; Developmental Studies Hybridoma Bank) that has proven to be a useful tool to examine En protein in diverse species as
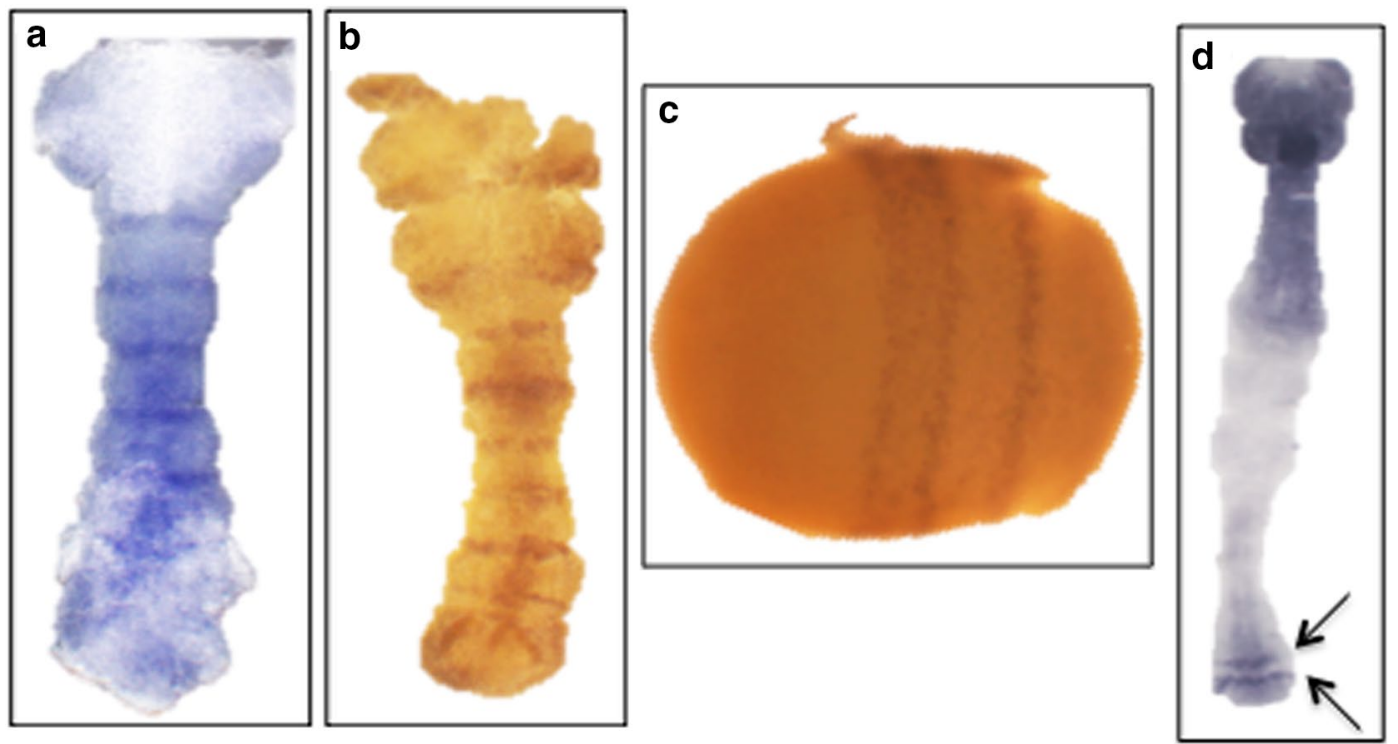

Fig. 1 Gene expression in H. halys embryos. a In situ hybridization in H. halys germ band embryos using an Hh-en probe. Six stripes were detected. The anterior and posterior parts of the embryo remained covered with yolk in this photograph. $\mathbf{b}$ En antibody staining to an embryo slightly older than that shown in (a). Nine stripes were observed. c A blastoderm stage embryo expressing three Hh-eve stripes in the central region of the embryo. d A germ band with two Hh-eve stripes at or near the segment addition zone. (a, b, d) anterior (top) to posterior (bottom); (c) embryo orientated anterior (left), posterior (right) 
it recognizes an epitope located in the variable region of the homeodomain of En and Inv proteins, and does not cross-react with other homeodomain proteins $[35,36]$. As shown in Fig. 1b, En protein was detected in stripes at the boundary of each segment, as expected and in keeping with the RNA pattern (Fig. 1a).

Together, these experiments establish methods to examine spatiotemporal patterns of gene expression in $H$. halys embryos. Embryo collection and fixation protocols were successfully established for $H$. halys embryos, and both antibody staining and in situ hybridization were carried out successfully. These methods are now available to examine the expression of additional genes.

\section{RNA interference is effective in H. halys}

RNAi is a useful method to knock down gene expression in both plants and animals. To determine whether RNAi can be an effective tool for $H$. halys, we tested whether injection of dsRNA into adult females caused defects in offspring, so-called parental RNAi (pRNAi), which has been shown to be effective in T. castaneum, D. maculatus, O. fasciatus and several other insect species [50-52]. To test this method, we sought a gene whose perturbation would result in very specific morphological defects, as opposed to general lethality, so that we could clearly assess the impacts of gene knockdown. For this purpose, we chose the homeotic gene Sex combs reduced (Scr). Scr, like other homeotic genes, is responsible for determining segmental identity in early embryos [53]. Inappropriate expression of homeotic genes result in transformation of one body part toward another body part and loss of homeotic function results in embryonic death (reviewed in [54]). Knockdown of Scr by RNAi was shown to have very clear and unique effects-the transformation of proboscis toward leg-in O. fasciatus ([55] and reproduced by us, Additional file 3: Figure 3), and in the American cockroach, Periplaneta americana [24]. To test RNAi in $H$. halys, a 327-bp Hh-Scr sequence, including 51 bp of the homeobox and 276 bp upstream, isolated by degenerate PCR, was extended based on transcriptome data to an 816-bp sequence including 76 bp of $5^{\prime}$ UTR and a coding region of 246 amino acids that includes the YPWM motif and part of the homeodomain. The homeodomain is $100 \%$ identical to a partial Scr gene (185 amino acids) that was isolated from the southern green stink bug (Nezara viridula) [56]. The partial homeodomain has an Scr signature sequence at the $\mathrm{N}$-terminal arm of the homeodomain (highlighted in Additional file 2: Figure 2c) and is $100 \%$ identical to that of D. melanogaster Scr.

As expected for RNAi, a range of defects was observed in $H h$-Scr pRNAi offspring. In the most severely affected embryos, death prior to hatching was observed. To examine defects, embryos were dissected out of unhatched eggs from Scr dsRNA-injected females. Many of these eggs were not fully developed, suggesting lethal effects of loss of $\mathrm{Scr}$ function in early embryogenesis. Some nearly hatched nymphs that were possible to remove from the egg cases lacked whole mouthparts (Fig. 2b, c).

Additional offspring of Scr dsRNA-injected females were observed with abnormalities indicative of homeotic transformation of the mouthparts (Fig. 3). The proboscis of wild-type first instar nymphs is needle-like in shape and has a sharp tip (Fig. 3a, black arrow). For offspring of $\mathrm{Scr}$ dsRNA-injected females, severely affected first
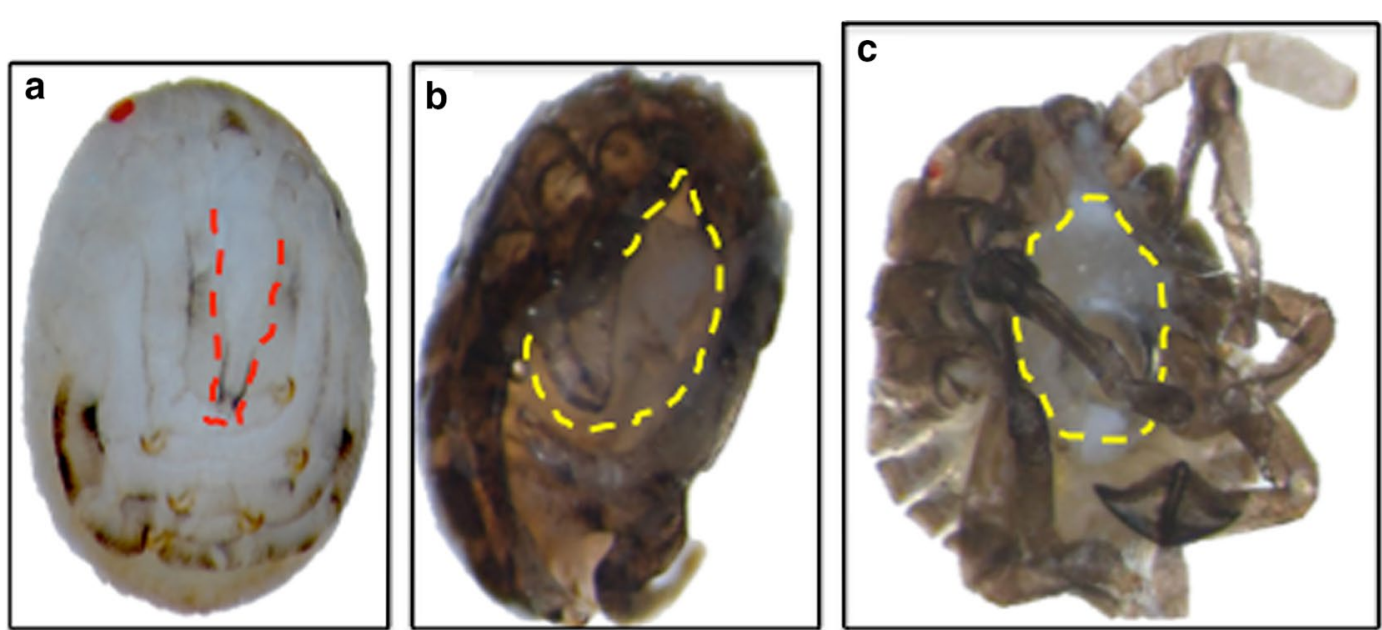

Fig. 2 Severe defects in unhatched offspring after Scr RNAi. Photographs of nymphs dissected out of egg cases are shown. a Control, gfppNAi is fully developed with proboscis (red dashed line). Note that wild-type animals darken after they hatch. $\mathbf{b}, \mathbf{c}$ Different examples of Hh-Scr pRNAi offspring with severely malformed or absent head structures (yellow dashed lines). These Hh-Scr ${ }^{\text {RNAAi }}$ embryos were presumably unable to hatch and therefore were still within the egg shell as they matured and darkened 

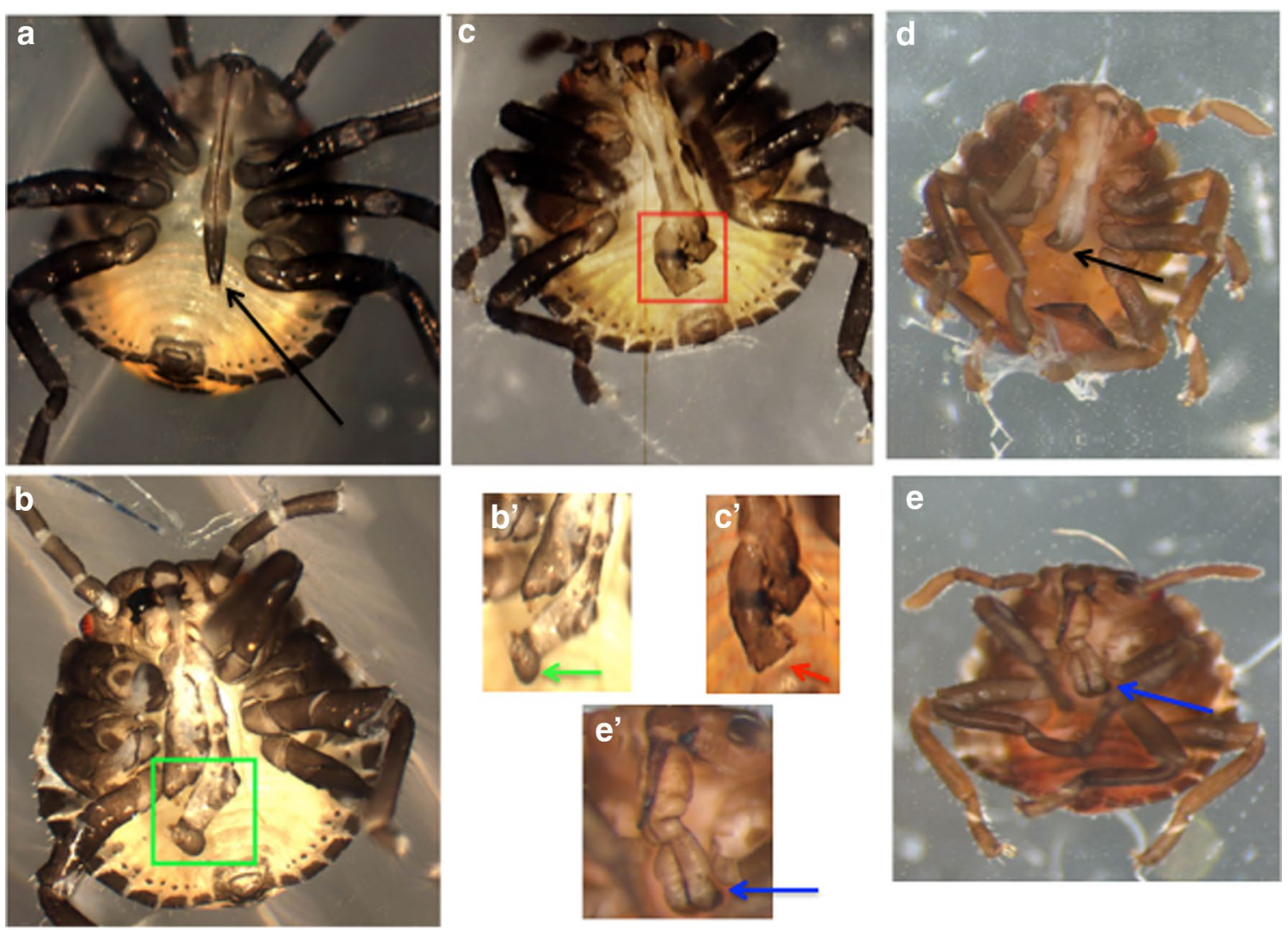

Fig. 3 Knockdown of Scr by RNAi produces abnormal mouthparts in H. halys. Photographs of first instar nymphs are shown. a Wild type. The proboscis has a needle-like shape with pointed tip (black arrow). b-g Offspring of females injected with Hh-Scr dsRNA (Scr pRNAi). b First instar nymph with severe effects has a bifurcated proboscis (green square); $\mathbf{b}^{\prime}$ tip of the proboscis from panel (b) (green arrow). c First instar nymph has a bluntended proboscis (red square); $\mathbf{c}^{\prime}$ tip of the proboscis from panel (c) (red arrow), $\mathbf{d}$ another example of a transformed proboscis with bent, abnormal tip (black arrow). e An example of a first instar nymph showing duplication and thickening at the tip of the proboscis (blue arrow). $\mathbf{e}^{\prime}$ Enlargement of region from panel (e) (blue arrow)

instar nymphs had a bifurcated proboscis, and claws were seen at the tip of the proboscis (data not shown), suggestive of homeotic transformation toward leg (Fig. 3b). Some first instar nymphs had less severe defects; for example, in some cases, instead of being bifurcated, the end of the proboscises expanded into a clubbed shape (Fig. 3c). Others had shorter or bent and twisted proboscises, with partial duplication or bifurcation of distal structures (Fig. 3d, e). Finally, other nymphs hatched with normal proboscises but with smaller and withered bodies.

Overall, while the defects observed were quite specific, the penetrance of defects varied in different experiments. In some cases, all fully-developed nymphs showed abnormal mouthparts. In other cases, while increased failure to hatch was observed, hatched larvae did not appear to have mouthpart abnormalities. In addition, in any one experiment, the severity of the defects attenuated as time went on, as was also observed for $O$. fasciatus and D. maculatus RNAi $[13,57]$. For example, embryos laid within the first 2 weeks after injection showed the most severe phenotypes (bifurcated proboscises); slightly later, embryos showed less severe phenotypes (clubbed shape proboscises); by the third week, embryos were all normal. In sum, RNAi was clearly effective in knocking down gene function in $H$. halys.

\section{Laboratory culture of $H$. halys}

Long-term rearing of laboratory cultures of $H$. halys has been reported by others but was extremely challenging in our hands. Following two different rearing regimes (see "Methods"), one of which has been successful for multiple generations elsewhere $[27,58]$, we failed to maintain a stable colony without supplementation from field-caught bugs for more than three generations (Fig. 4). While we were unable to determine the cause of this colony collapse, potential causes include inbreeding depression, infection, and/or loss of symbionts over time [26]. This finding hampers experimentation because it limits the number of eggs that can be collected and the need for 


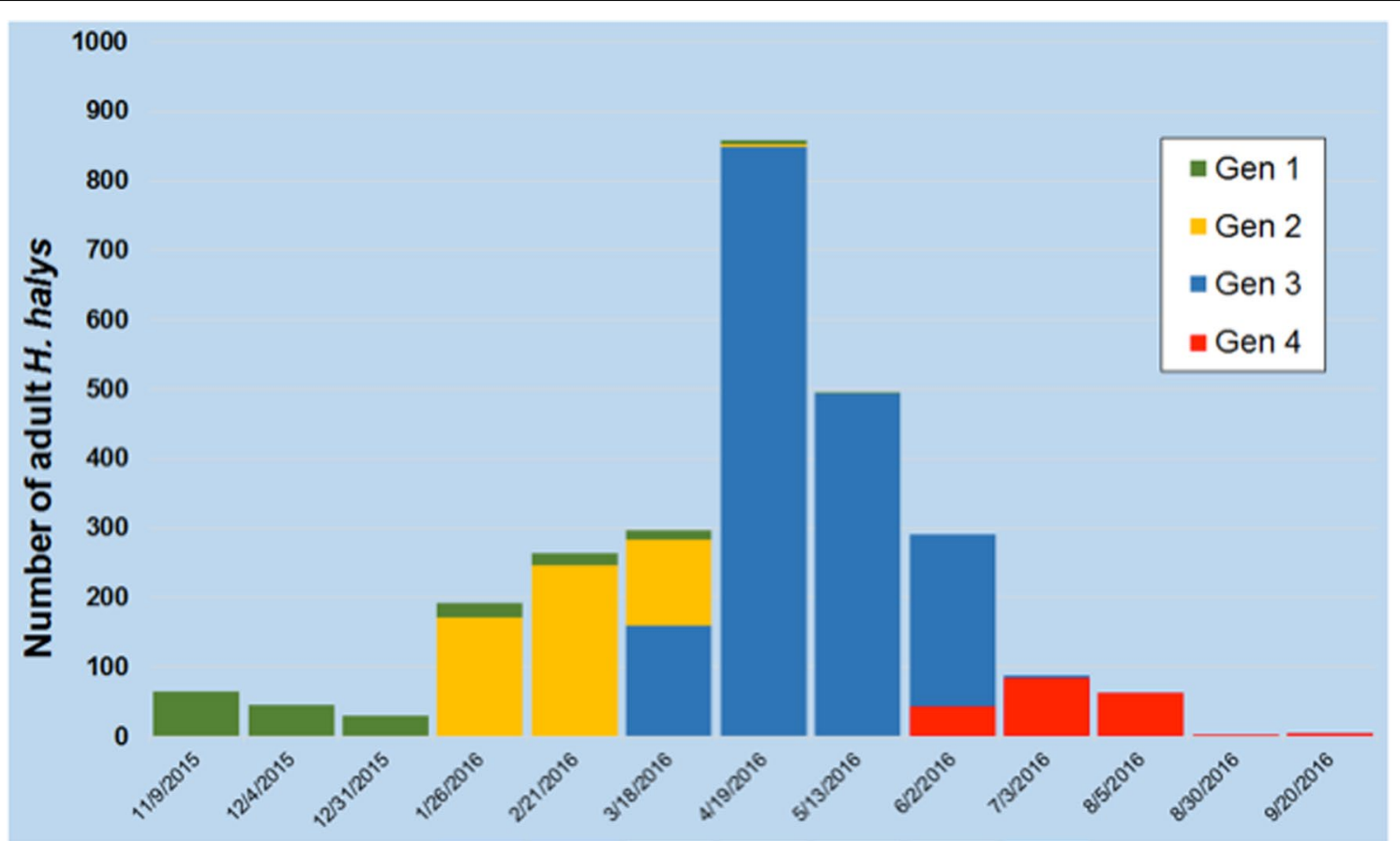

Fig. 4 Long-term rearing of H. halys in culture. The number of H. halys adults in our lab colony is shown over time. From the egg masses obtained from Dr. Don Weber's laboratory, 64 adults emerged (generation 1). A steady increase in adults was seen in generation 2, as expected. About 2 months later, generation 3 reached its peak at 849 adults. Following this point, our lab population experienced severe decline, with generation 4 peaking at 84 adults. This decimation was accompanied by adults displaying malformed wings and small body size

supplementation from outside increases heterozygosity within the colony. However, $H$. halys can be stored long term in diapause and will breed actively after this, allowing supplementation from a single wild-caught population, that in some places are so dense that it is possible to collect thousands of individuals at peak season [59]. In addition, fresh $H$. halys from different geographical regions can be caught during the spring and summer, as well as in the early fall when they congregate in human-made structures. Thus, with one generation every $<2$ months, it is possible to expand colonies during the active seasons and maintain them through the winter.

These endeavors raise questions about what defines and what is necessary for the establishment of a species as a new, effective 'model system,' a topic that has been discussed in recent literature [60-64]. The most well-developed, traditional animal systems-flies, worms, mice-share features such as stable laboratory culture, rapid life cycles, history of genetic tools, and large amounts of genomic information, including wellannotated genomes, transcriptomes, ChIP data, publically available stocks, and more. These species form the backbone, or serve as reference points, for research in their relative phyla and beyond. However, we take the view that for comparative studies, the level of sophistication seen for these systems is not required. Techniques necessary to answer specific questions can be developed for individual species without the labor-intensive, longterm investments that have been made by communities of researchers for flies, worms and mice. This will allow for broader explorations of mechanistic diversity within realistic time frames. For $H$. haly, transcriptome data have been published $[28,58]$, genome sequencing is in progress [18], and we have developed the molecular tools to make use of its important point in insect phylogeny. The evo-devo field has benefited enormously from studies of seasonally collected species including, to name only a few, ctenophores [65, 66], hemichordates (e.g., [67]; echinoderms [68]; cephalochordates [69]; the centipede, Strigamia maritima [70], or the onychophoran Euperipatoides kanangrensis [71] and many others, for which long-term laboratory culture has been unsuccessful or is simply not practical. Although one advantage of insect systems is the ease with which they are cultured in the laboratory, this thinking may reflect a $D$. melanogastercentric bias that could have the unexpected negative consequence of limiting studies of mechanistic biodiversity.

\section{Conclusions}

We and others have taken advantage of molecular genetic techniques to analyze gene expression and function in diverse insect species. Here we present methods to 
analyze the expression patterns of genes in developing embryos (Figs. 1) and to study gene function by RNAi (Figs. 2, 3) in $H$. halys. The methods presented will allow other researchers in the field to expand studies of basic genetics and biology of $H$. halys. In addition, the establishment of RNAi in this species opens up the possibility of using this as a strategy for controlling $H$. halys pests in the field, an approach of increasing interest in recent years (reviewed in [72, 73]). As mentioned above, Hemiptera is a large insect order, closely related to the holometabolous insects. Here we have presented what is, to our knowledge, the first set of molecular methods to study development of a representative of the stink bug family Pentatomidae, a large family within the superfamily Pentatomoidea, which includes $\sim 7000$ species. Future comparative analysis will provide insight into the novel and derived regulatory mechanisms in this large clade.

\section{Additional files}

Additional file 1: Figure 1. Injection of dsRNA into $H$. halys adult females. dsRNA was injected into the abdomen of a female $H$. halys with a Hamilton syringe. The injection point is located between the $3 \mathrm{r}^{\mathrm{d}}$ and $4 \mathrm{t}^{\mathrm{h}}$ abdominal sterna, away from the ventral midline. The tip of the needle is held directly above the point of injection.

Additional file 2: Figure 2. Conceptual translation and sequence comparison for $\mathrm{H}$. halys genes isolated in this study. Translations of the isolated $H$. halys sequences are highlighted in yellow in each alignment. (A) Amino acid alignments for $\mathrm{Hh}$-En and Inv. The isolated $H$. halys sequence does not encode the RS-motif which is characteristic of holometabolous Inv proteins (arrowhead). (B) Alignment of the homeodomain of several Eve proteins. (C) A cDNA encoding a 246 amino acid portion of $\mathrm{Hh}$-Scr, including part of the homeodomain, was isolated. Scr amino acid alignment shows strong conservation around the YPWM motif and the homeodomain. The homeodomain N-terminal Scr signature sequence is highlighted in blue [74]. Species abbreviations are as follows: Bmor: Bombyx mori; Dmel: Drosophila melanogaster; Gbim:Gryllus bimaculatus; Hhal: Halyomorpha halys; Ofas: O. fasciatus fasciatus; Pame: Periplaneta americana; Sgre: Schistocerca gregaria; Tcas: Tribolium castaneum.

Additional file 3: Figure 3. Knockdown of Scr in O. fasciatus. Scr was chosen as a standard to test RNAi in H. halys because of the clear phenotype observed in 0 . fasciatus [15]. These results were repeated in our lab for comparison to H. halys. Photos of $1 s^{t}$ instar nymphs are shown. (A) Wild type. The proboscis has a needle-like shape with pointed tip; $(B, C)$ Offspring of females injected with Of-Scr dsRNA. (B) $1 s^{\mathrm{t}}$ instar nymph with severe effects has a bifurcated proboscis (red square); (C) $1 s^{t}$ instar nymph with less severe phenotype has a duplication at the end of the proboscis (red arrow).

\section{Authors' contributions}

$\mathrm{LP}$ conceived and designed research. MC, YL, and KR conducted experiments. All authors analyzed data. YL and LP wrote the manuscript. All authors read and approved the final manuscript.

\section{Author details}

${ }^{1}$ Department of Entomology, University of Maryland, College Park, MD 20742, USA. ${ }^{2}$ Present Address: Department of Anesthesiology, Stony Brook Medicine, 101 Nicolls Rd, Stony Brook, NY 11794, USA.

\section{Acknowledgements}

We are grateful to Galen Dively for help with $H$. halys rearing, support, advice and suggestions. We thank Alys Jarvela for comments on the manuscript and
Drs. Tom Dorsey, Don Weber, and Yong-Lak Park for providing H. halys eggs and rearing protocols.

\section{Competing interests}

The authors declare that they have no competing interests.

\section{Availability of data and materials}

All data generated or analyzed during this study are included in this published article [and its supplementary information files]. Any additional methods, protocols or suggestions are available upon request.

\section{Consent for publication}

Not applicable.

\section{Ethics approval and consent to participate}

Not applicable.

\section{Funding}

This work was supported by Grants from the United States Department of Agriculture-National Institute of Food and Agriculture (USDA-NIFA) Specialty Crop Research Initiative (SCRI) \#2011-51181-30937 and from the National Institutes of Health (R01GM113230 to L.P.). The funding agencies played no direct role in this research.

\section{Publisher's Note}

Springer Nature remains neutral with regard to jurisdictional claims in published maps and institutional affiliations.

Received: 12 July 2017 Accepted: 4 October 2017

Published online: 18 October 2017

\section{References}

1. Green MM. 2010: A century of Drosophila genetics through the prism of the white gene. Genetics. 2010;184(1):3-7.

2. Mohr SE, Hu Y, Kim K, Housden BE, Perrimon N. Resources for functional genomics studies in Drosophila melanogaster. Genetics. 2014;197(1):1-18.

3. Hales KG, Korey CA, Larracuente AM, Roberts DM. Genetics on the fly: a primer on the Drosophila model system. Genetics. 2015;201(3):815-42.

4. Ugur B, Chen K, Bellen HJ. Drosophila tools and assays for the study of human diseases. Dis Model Mech. 2016;9(3):235-44.

5. Pick L. Fly models of human diseases. In: Wassarman PM, editor. Current topics in developmental biology, vol. 121. Cambridge: Elsevier; 2017.

6. Brown SJ, Shippy TD, Miller S, Bolognesi R, Beeman RW, Lorenzen MD, Bucher G, Wimmer EA, Klingler M. The red flour beetle, Tribolium castaneum (Coleoptera): a model for studies of development and pest biology. Cold Spring Harbor Protoc. 2009. doi:10.1101/pdb.emo126.

7. Richards S, Gibbs RA, Weinstock GM, Brown SJ, Denell R, Beeman RW, Gibbs R, Bucher G, Friedrich M, Grimmelikhuijzen CJ, Klingler M, Lorenzen M, Roth S, Schroder R, Tautz D, Zdobnov EM, Muzny D, Attaway T, Bell S, Buhay CJ, Chandrabose MN, Chavez D, Clerk-Blankenburg KP, Cree A, Dao M, Davis C, Chacko J, Dinh H, Dugan-Rocha S, Fowler G, Garner TT, Garnes J, Gnirke A, Hawes A, Hernandez J, Hines S, Holder M, Hume J, Jhangiani SN, Joshi V, Khan ZM, Jackson L, Kovar C, Kowis A, Lee S, Lewis LR, Margolis J, Morgan M, Nazareth LV, Nguyen N, Okwuonu G, Parker D, Ruiz SJ, Santibanez J, Savard J, Scherer SE, Schneider B, Sodergren E, Vattahil S, Villasana D, White CS, Wright R, Park Y, Lord J, Oppert B, Brown S, Wang L, Weinstock G, Liu Y, Worley K, Elsik CG, Reese JT, Elhaik E, Landan G, Graur D, Arensburger P, Atkinson P, Beidler J, Demuth JP, Drury DW, Du YZ, Fujiwara H, Maselli V, Osanai M, Robertson HM, Tu Z, Wang JJ, Wang S, Song H, Zhang L, Werner D, Stanke M, Morgenstern B, Solovyev V, Kosarev P, Brown G, Chen HC, Ermolaeva O, Hlavina W, Kapustin Y, Kiryutin B, Kitts P, Maglott D, Pruitt K, Sapojnikov V, Souvorov A, Mackey AJ, Waterhouse RM, Wyder S, Kriventseva EV, Kadowaki T, Bork P, Aranda M, Bao R, Beermann A, Berns N, Bolognesi R, Bonneton F, Bopp D, Butts T, Chaumot A, Denell RE, Ferrier DE, Gordon CM, Jindra M, Lan Q, Lattorff HM, Laudet V, von Levetsow C, Liu Z, Lutz R, Lynch JA, da Fonseca RN, Posnien N, Reuter R, Schinko JB, Schmitt C, Schoppmeier M, Shippy TD, 
Simonnet F, Marques-Souza H, Tomoyasu Y, Trauner J, Van der Zee M, Vervoort M, Wittkopp N, Wimmer EA, Yang X, Jones AK, Sattelle DB, Ebert PR, Nelson D, Scott JG, Muthukrishnan S, Kramer KJ, Arakane Y, Zhu Q, Hogenkamp D, Dixit R, Jiang H, Zou Z, Marshall J, Elpidina E, Vinokurov K, Oppert C, Evans J, Lu Z, Zhao P, Sumathipala N, Altincicek B, Vilcinskas A, Williams M, Hultmark D, Hetru C, Hauser F, Cazzamali G, Williamson M, Li B, Tanaka Y, Predel R, Neupert S, Schachtner J, Verleyen P, Raible F, Walden KK, Angeli S, Foret S, Schuetz S, Maleszka R, Miller SC, Grossmann D. The genome of the model beetle and pest Tribolium castaneum. Nature. 2008;452(7190):949-55.

8. Cryan JR, Urban JM. Higher-level phylogeny of the insect order Hemiptera: is Auchenorrhyncha really paraphyletic? Syst Entomol. 2011;37:7-21.

9. Weirauch C, Schuh RT. Systematics and evolution of heteroptera: 25 years of progress. Annu Rev Entomol. 2011;56:487-510.

10. Cholewinski M, Derda M, Hadas E. Parasitic diseases in humans transmitted by vectors. Ann Parasitol. 2015;61(3):137-57.

11. Nunes-da-Fonseca R, Berni M, Tobias-Santos V, Pane A, Araujo HM. Rhodnius prolixus: from classical physiology to modern developmental biology. Genesis. 2017. doi:10.1002/dvg.22995.

12. Lawrence PA. The structure and properties of a compartment border: the intersegmental boundary in Oncopeltus. Ciba Found Symp. 1975;29:3-23.

13. Angelini DR, Kaufman TC. Functional analyses in the hemipteran Oncopeltus fasciatus reveal conserved and derived aspects of appendage patterning in insects. Dev Biol. 2004;271(2):306-21.

14. Angelini DR, Kaufman TC. Functional analyses in the milkweed bug Oncopeltus fasciatus (Hemiptera) support a role for Wnt signaling in body segmentation but not appendage development. Dev Biol. 2005;283(2):409-23

15. Chesebro J, Hrycaj S, Mahfooz N, Popadic A. Diverging functions of Scr between embryonic and post-embryonic development in a hemimetabolous insect, Oncopeltus fasciatus. Dev Biol. 2009;329(1):142-51.

16. Stahi R, Chipman AD. Blastoderm segmentation in Oncopeltus fasciatus and the evolution of insect segmentation mechanisms. Proc Biol Sci. 2016. doi:10.1098/rspb.2016.1745.

17. Liu J, Lemonds TR, Marden JH, Popadic A. A pathway analysis of melanin patterning in a hemimetabolous insect. Genetics. 2016;203(1):403-13.

18. i5K Consortium. The i5K Initiative: advancing arthropod genomics for knowledge, human health, agriculture, and the environment. J Hered. 2013;104(5):595-600.

19. Kumar S, Stecher G, Suleski M, Hedges SB. TimeTree: a resource for timelines, timetrees, and divergence times. Mol Biol Evol. 2017;34(7):1812-9.

20. Nielsen AL, Hamilton GC. Life history of the invasive species Halyomorpha halys (Hemiptera: Pentatomidae) in northeastern United States. Ann Entomol Soc Am. 2009:102:608-16.

21. Leskey TC, Short BD, Butler BB, Wright SE. Impact of the invasive brown marmorated stink bug, Halyomorpha halys (Stål) in mid-Atlantic tree fruit orchards in the United States: case studies of commercial management. Psyche. 2012. doi:10.1155/2012/535062.

22. Leskey TC, Hamilton GC, Nielsen AL, Polk DF, Rodriguez-Saona C, Bergh $\mathrm{JC}$, et al. Pest status of the brown marmorated stink bug, Halyomorpha halys (Stål), in the USA. Outlooks Pest Manag. 2012;23:218-66

23. Haye T, Weber DC. Special issue on the brown marmorated stink bug, Halyomorpha halys: an emerging pest of global concern. J Pest Sci. 2017;90:987-8.

24. Hrycaj S, Chesebro J, Popadic A. Functional analysis of Scr during embryonic and post-embryonic development in the cockroach, Periplaneta americana. Dev Biol. 2010:341 (1):324-34.

25. Passalacqua KD, Hrycaj S, Mahfooz N, Popadic A. Evolving expression patterns of the homeotic gene Scr in insects. Int J Dev Biol. 2010;54(5):897-904.

26. Taylor CM, Coffey PL, DeLay BD, Dively GP. The importance of gut symbionts in the development of the brown marmorated stink bug, Halyomorpha halys (Stal). PLOS ONE. 2014;9(3):e90312.

27. Khrimian A, Zhang A, Weber DC, Ho HY, Aldrich JR, Vermillion KE, Siegler MA, Shirali S, Guzman F, Leskey TC. Discovery of the aggregation pheromone of the brown marmorated stink bug (Halyomorpha halys) through the creation of stereoisomeric libraries of 1-bisabolen-3-ols. J Nat Prod. 2014;77(7):1708-17.

28. Ioannidis P, Lu Y, Kumar N, Creasy T, Daugherty S, Chibucos MC, Orvis J, Shetty A, Ott S, Flowers M, Sengamalay N, Tallon LJ, Pick L, Dunning Hotopp JC. Rapid transcriptome sequencing of an invasive pest, the brown marmorated stink bug Halyomorpha halys. BMC Genom. 2014;15:738.

29. Altschul SF, Gish W, Miller W, Myers EW, Lipman DJ. Basic local alignment search tool. J Mol Biol. 1990;215(3):403-10.

30. Ben-David J, Chipman AD. Mutual regulatory interactions of the trunk gap genes during blastoderm patterning in the hemipteran Oncopeltus fasciatus. Dev Biol. 2010;346(1):140-9.

31. Peel AD, Telford MJ, Akam M. The evolution of hexapod engrailed-family genes: evidence for conservation and concerted evolution. Proc Biol Sci. 2006;273(1595):1733-42.

32. Hui CC, Matsuno K, Ueno K, Suzuki Y. Molecular characterization and silk gland expression of Bombyx engrailed and infected genes. Proc Natl Acad Sci USA. 1992;89(1):167-71.

33. Kornberg T. Engrailed: a gene controlling compartment and segment formation in Drosophila. Proc Natl Acad Sci USA. 1981;78(2):1095-9.

34. O"arrell PH, Desplan C, DiNardo S, Kassis JA, Kuner JM, Sher E, Theis J, Wright D. Embryonic pattern in Drosophila: the spatial distribution and sequence-specific DNA binding of engrailed protein. Cold Spring Harb Symp Quant Biol. 1985;50:235-42.

35. Patel NH, Kornberg TB, Goodman CS. Expression of engrailed during segmentation in grasshopper and crayfish. Development. 1989:107(2):201-12.

36. Patel NH, Martin-Blanco E, Coleman KG, Poole SJ, Ellis MC, Kornberg TB, Goodman CS. Expression of engrailed proteins in arthropods, annelids, and chordates. Cell. 1989;58(5):955-68.

37. Brown SJ, Patel NH, Denell RE. Embryonic expression of the single Tribolium engrailed homolog. Dev Genet. 1994;15(1):7-18.

38. Peterson MD, Popadic A, Kaufman TC. The expression of two engrailedrelated genes in an apterygote insect and a phylogenetic analysis of insect engrailed-related genes. Dev Genes Evol. 1998;208(10):547-57.

39. Damen WG, Janssen R, Prpic NM. Pair rule gene orthologs in spider segmentation. Evol Dev. 2005;7(6):618-28.

40. Choe CP, Miller SC, Brown SJ. A pair-rule gene circuit defines segments sequentially in the short-germ insect Tribolium castaneum. Proc Natl Acad Sci USA. 2006;103(17):6560-4.

41. Heffer A, Xiang J, Pick L. Variation and constraint in Hox gene evolution. Proc Natl Acad Sci USA. 2013;110(6):2211-6.

42. Green J, Akam M. Evolution of the pair rule gene network: insights from a centipede. Dev Biol. 2013;382(1):235-45.

43. Rosenberg MI, Brent AE, Payre F, Desplan C. Dual mode of embryonic development is highlighted by expression and function of Nasonia pairrule genes. Elife. 2014;3:e01440.

44. Davis GK, Patel NH. Short, long, and beyond: molecular and embryological approaches to insect segmentation. Annu Rev Entomol. 2002;47:669-99.

45. Liu PZ, Kaufman TC. Short and long germ segmentation: unanswered questions in the evolution of a developmental mode. Evol Dev. 2005;7(6):629-46.

46. Macdonald PM, Ingham P, Struhl G. Isolation, structure, and expression of even-skipped: a second pair-rule gene of Drosophila containing a homeo box. Cell. 1986:47(5):721-34.

47. Liu PZ, Kaufman TC. Even-skipped is not a pair-rule gene but has segmental and gap-like functions in Oncopeltus fasciatus, an intermediate germband insect. Development. 2005;132(9):2081-92.

48. Patel NH, Ball EE, Goodman CS. Changing role of even-skipped during the evolution of insect pattern formation. Nature. 1992;357(6376):339-42.

49. Xiang J, Reding K, Heffer A, Pick L, Conservation and variation in pair-rule gene expression and function in the intermediate-germ beetle Dermestes maculatus. Development 2017 (in press)

50. Liu PZ, Kaufman TC. Hunchback is required for suppression of abdominal identity, and for proper germband growth and segmentation in the intermediate germband insect Oncopeltus fasciatus. Development. 2004;131(7):1515-27.

51. Bucher G, Scholten J, Klingler M. Parental RNAi in Tribolium (Coleoptera). Curr Biol. 2002;12:R85-6.

52. Xiang J, Reding K, Pick L. Rearing and double-stranded RNA-mediated gene knockdown in the hide beetle, Dermestes maculatus. J Vis Exp. 2016. doi:10.3791/54976.

53. Pattatucci AM, Oteson DC, Kaufman TC. A functional and structural analysis of the Sex combs reduced locus of Drosophila melanogaster. Genetics. 1991;129:423-41. 
54. Gehring WJ. Homeotic genes, the homeo box, and the genetic control of development. Cold Spring Harb Symp Quant Biol. 1985;50:243-51.

55. Hughes CL, Kaufman TC. RNAi analysis of deformed, proboscipedia and Sex combs reduced in the milkweed bug Oncopeltus fasciatus: novel roles for Hox genes in the hemipteran head. Development. 2000;127(17):3683-94.

56. Tian X, Xie Q, Li M, Gao C, Cui Y, Xi L, Bu W. Phylogeny of pentatomomorphan bugs (Hemiptera-Heteroptera: Pentatomomorpha) based on six Hox gene fragments. Zootaxa. 2011;2888:57-68.

57. Xiang J, Forrest IS, Pick L. Dermestes maculatus: an intermediate-germ beetle model system for evo-devo. Evodevo. 2015:6:32

58. Sparks ME, Shelby KS, Kuhar D, Gundersen-Rindal DE. Transcriptome of the invasive brown marmorated stink bug, Halyomorpha halys (Stal) (Heteroptera: Pentatomidae). PLoS ONE. 2014;9(11):e111646.

59. Taylor CM, Coffey PL, Hamby KA, Dively GP. Laboratory rearing of Halyomorpha halys: methods to optimize survival and fitness of adults during and after diapause. J Pest Sci. 2017. doi:10.1007/s10340-017-0881-9.

60. Hughes CL, Kaufman TC. A diverse approach to arthropod development. Evol Dev. 2000;2(1):6-8.

61. Jenner RA, Wills MA. The choice of model organisms in evo-devo. Nat Rev Genet. 2007;8(4):311-9.

62. Abzhanov A, Extavour CG, Groover A, Hodges SA, Hoekstra HE, Kramer EM, Monteiro A. Are we there yet? Tracking the development of new model systems. Trends Genet. 2008;24(7):353-60.

63. Sommer RJ. The future of evo-devo: model systems and evolutionary theory. Nat Rev Genet. 2009;10(6):416-22.

64. Goldstein B, King N. The future of cell biology: emerging model organisms. Trends Cell Biol. 2016;26(11):818-24.

65. Schnitzler CE, Simmons DK, Pang K, Martindale MQ, Baxevanis AD. Expression of multiple Sox genes through embryonic development in the ctenophore Mnemiopsis leidyi is spatially restricted to zones of cell proliferation. Evodevo. 2014;5:15.

66. Pang K, Martindale MQ. Comb jellies (ctenophora): a model for Basal metazoan evolution and development. CSH Protoc. 2008. doi:10.1101/ pdb.emo106.

67. Gonzalez P, Uhlinger KR, Lowe CJ. The adult body plan of indirect developing hemichordates develops by adding a Hox-patterned trunk to an anterior larval territory. Curr Biol. 2017;27(1):87-95.

68. Cheatle Jarvela AM, Hinman V. A method for microinjection of Patiria miniata zygotes. J Vis Exp. 2014;91:e51913.

69. Holland LZ, Onai T. Early development of cephalochordates (amphioxus). Wiley Interdiscip Rev Dev Biol. 2012;1(2):167-83.

70. Chipman AD, Arthur W, Akam M. Early development and segment formation in the centipede, Strigamia maritima (Geophilomorpha). Evol Dev. 2004;6(2):78-89.

71. Janssen R, Budd GE. Deciphering the onychophoran "egmentation gene cascade": gene expression reveals limited involvement of pair rule gene orthologs in segmentation, but a highly conserved segment polarity gene network. Dev Biol. 2013;382(1):224-34.

72. Joga MR, Zotti MJ, Smagghe G, Christiaens O. RNAi efficiency, systemic properties, and novel delivery methods for pest insect control: what we know so far. Front Physiol. 2016;7:553.

73. Zhang J, Khan SA, Heckel DG, Bock R. Next-generation insectresistant plants: RNAi-mediated crop protection. Trends Biotechnol. 2017;35(9):871-82.

74. Furukubo-Tokunaga K, Muller M, Affolter M, Pick L, Kloter U, Gehring WJ. In vivo analysis of the helix-turn-helix motif of the fushi tarazu homeo domain of Drosophila melanogaster. Genes Dev. 1992;6(6):1082-96.

\section{Submit your next manuscript to BioMed Central and we will help you at every step:}

- We accept pre-submission inquiries

- Our selector tool helps you to find the most relevant journal

- We provide round the clock customer support

- Convenient online submission

- Thorough peer review

- Inclusion in PubMed and all major indexing services

- Maximum visibility for your research

Submit your manuscript at www.biomedcentral.com/submit

(O) BioMed Central 